\title{
Networks in Biology - From Identification, Analysis to Interpretation
}

\author{
Jesper Tegnér \\ Institutionen för Medicin \\ Karolinska Universitetssjukhuset \\ Solna, Stockholm \\ jesper.tegner@ki.se
}

\begin{abstract}
Over the last decade networks has become a unifying language in biology. Yet we are only in the beginning of understanding their significance for biology and their medical applications. I will talk about the diversity of biological networks composed either of genes, proteins, metabolites, or cells and the associated methods for finding these graphs in the data. Next I will provide an overview of different methods of analysis and what kind of insights that have been obtained. During the talk I will highlight current challenging problems requiring computational skills with respect to identification, analysis, algorithms, visualization and software.
\end{abstract}

